LITERATURA 



\title{
THE BUENOS AIRES AFFAIR: PARODIA Y PUESTA EN ABISMO. OLVIDO DE AMOR NO CORRESPONDIDO
}

\author{
Raimy Camacho Ramírez
}

\begin{abstract}
RESUMEN
Este articulo muestra la conexión existente entre los epígrafes y la trama en la novela The Buenos Aires Affair de Manuel Puig. Ello consiste en la reiteración de detalles de los epígrafes pero en la trama, este acto se denomina "mise en abyme". En este caso, trataremos, por un lado, la repetición del nombre propio; y, por otro lado, el olvido de este. Ambos, contribuyen a dibujar una imagen paródica del personaje Gladys Hebe Onofrio por contraste con las imágenes gloriosas de las divas de los paratextos.

Palabras clave: mise en abyme, nombre propio, repetición, diva, olvido.
\end{abstract}

\begin{abstract}
This article demonstrates that there exist a connection between epigraphs and the plot in the novel The Buenos Aires Affair by Manuel Puig. The bond mentioned above is called "mise en abyme" which means that paragraphs and the action of the story show some features in common. We will analyse two features: In one hand, the use of the proper noun by itself; and, on the other hand, his omission. This two facts help to built up the parodic contrast between the main character, Gladys Hebe Onofrio, and the film stars in the epigraphs.

Key words: mise en abyme, proper noun, repetition, diva, omission.
\end{abstract}

\section{Introducción}

La novela The Buenos Aires Affair de Manuel Puig es, por la manera como fue clasificada editorialmente y desde su origen, una novela policíaca; sin embargo, una lectura detallada revela que más bien es una parodia de este género (Kerr 1987:132). Esto sucede porque se cuenta la historia de un crimen que nunca acontece, aunque se prepare el escenario y se construya una especie de intriga en torno a este acontecimiento. Esta "repetición imperfecta" se refleja en varios

M.L. Raimy Camacho Ramírez. Profesor de Comunicación y Lenguaje, Escuela de Estudios Generales. Universidad de Costa Rica, Sede del Atlántico.

Correo electrónico: maitreya05@yahoo.com

Recepción: 21- 5- 2009

Aceptación: 16- 6- 2009 
niveles de la obra, tanto en la presentación de estrellas del cine en los epígrafes y su relación con Gladys Hebe Onofrio, como en la divergencia del título y la novela.

La obra "se roba" pequeñas escenas de obras clásicas de cine y las transcribe como cita textual al comienzo de cada capítulo. Esto significa que, al principio de la novela, el texto hace referencias a películas de Hollywood, las cuales muestran a una "diva del cine" como figura principal; consecuentemente, estas "miniaturas visuales" se repiten metafóricamente a través de la trama y el artículo pretende demostrar este hecho.

Este hecho tiene un orden particular, esto significa que la joven escultora es un reflejo de las "Divas" y no viceversa ya que los epígrafes se adelantan, aclaran y explican la trama debido a su posición de siempre en exergo (Genette 1987:134-140). Como tratamos con una novela compleja, suceden eventos en diversos niveles del sistema y se entrecruzan. A manera de ejemplo, Gladys es producto de la "mise en abyme" de las divas de los epígrafes y, en otro lugar, ella copia, con lápices de color, imágenes de actrices. En otro nivel de complejidad, ella elabora esculturas con los despojos que deja la marea. Finalmente, la joven escultora es un producto elaborado con retazos de estrellas.

En este caso estamos afirmando que Gladys es una parodia de "Diva" porque ella está construida con retazos de esas "gloriosas actrices" y porque el resultado de este "collage" es una "mujer, tuerta y carente de talento real", como ella misma se autodenomina. Esta construcción es muy compleja pues, además de ser parodia, también es mise en abyme, ya que además de reconstruir a la joven escultora, también, al igual que la Marilyn de Wharhol, la repite de diversas formas.

Trabajamos una novela compleja y llena de repeticiones, las cuales incluyen desde eventos diegéticos hasta detalles aparentemente insignificantes; para ser más preciso, nos referimos por un lado a los dos crímenes: el del decampado - cometido por Leo- y el anunciado por la radio; por otro, a la reiteración del olor de las axilas y la aparición falsamente misteriosa de unas tijeras toledanas. Estos rasgos nos llevan a poner atención a detalles que, analizados cuidadosamente, revelan una conexión en mise en abyme.

\section{La parodia del mise en abyme}

Lucien Dallënbach define la mise en abyme como "todo enclave que guarde relación de similitud con la obra que lo contiene" (Dällenbach 1991:16). La definición fundamental de este término describiría solamente el reflejo de la totalidad del relato en un pequeño fragmento; es decir, el caso típico describiría obras como Hamlet, en las cuales aparece una pequeña historia que remite a la totalidad. Entonces, la definición original va más allá de la simple repetición de "una forma dentro de otra" y abarca más detalles que pueden considerarse como "puesta en abismo".

Jean Ricardou agrega que "mise en abyme" es "Aussi, tout ce qui se plaît, dans le texte, à établir quelque instance une relation de similitude..." con otras partes de la obra (Meyer 2004). Esto significa que no solo los elementos que se conectan obvia y directamente se incluyen como mise en abyme, sino también otros que aparentan ser no tan evidentes. La mise en abyme sucede al tomar como tema ciertas partes o todo el relato mismo (Meyer 2004).

Por su parte, la mise en abyme presenta los aspectos estructurales de la narración: "Le référent doit concerner le récit entier, mais il n'en représentera toujour qu' un aspect: structure, fil principal de l' histoire, mode de narration dominant, vision de quelque protagoniste" (Meyer 2004). En este caso particular se va a referir a la trama, al puro devenir de acontecimientos. 
Es un hecho que el metarrelato es un tipo de mise en abyme; entonces, todo metarrelato es mise en abyme, pero no todo mise en abyme es metarrelato. Esta forma literaria puede suceder en el nivel de una imagen o una metáfora, y no necesariamente como una historia dentro de otra historia. Por esta razón, para John White es "exclusively a form of literary reflexivity" (Gabrielle 2005: 31) de la misma manera como existen otros elementos que producen este efecto.

En realidad, la puesta es abismo es un entrecruzamiento de diversas estructuras narrativas que podrían incluir un relato pero pueden abarcar mucho más que eso. Richard Cardwell la define como «a series of apparently endlessly overlapping, enclosed networks of conceptual or structural spaces which form a kind of labyrinth leading to a shifting, everunattainable nucleus or centre» (Gabrielle 2005:31).

Para que exista mise en abyme deben suceder dos operaciones: la reducción o reestructuración por encaje y elaboración del paradigma de referencia; estas, tienen lugar por analogía y contraste. La citada transformación va "desde la reproducción cuasi mimética a la libre transformación" (Dällenbach 1991:22). El mecanismo estético se entiende si revisamos las Seis funciones del Lenguaje de Jacobson y nos centramos en la Función Poética.

Esta permite comprender cómo por medio del mecanismo de elección y combinación se establece una especie de vínculo paradigmático entre un acontecimiento y otro en la novela. Por medio de funciones y formas similares puede descubrirse la serie de puestas en abismo que se dan en una obra. Dällenbach explica que "la verdadera significancia del texto estriba en la coherencia de forma a forma y (...) en el hecho de que el texto repita de aquello de que está hablando, a pesar de las continuas variaciones en la manera de decir" (Dällenbach 1991: 64). Esa serie de reiteraciones permiten descubrir esas formas ocultas de confusión de planos que se dan en la narración.

\section{Mise en abyme paródica: El olvido y el nombre propio}

Desde la portada, se le plantea al lector un problema con el "nombre" The Buenos Aires Affair. Más precisamente, el título de la obra está escrito en inglés; por lo tanto, su vínculo con el universo cultural humano va a estar "estigmatizado" por esta lengua. Por el contrario, la historia se cuenta, desde luego, en español, con su consecuente efecto de lectura. Esa bifacialidad hace parecer que la trama se encuentra escrita en una lengua en la que no lo está. Esta doble superficie no es fortuita porque se repite de diversas maneras en la novela.

El estudio detallado revela un texto que adquiere un nivel inesperado de complejidad de significado por la serie de conexiones y repeticiones que suceden en varios niveles diegéticos. Ello nos permite determinar que la obra reitera no solo paródicamente a Gladys, también realiza el mismo trabajo con otra serie de “imágenes”. En otras palabras, los epígrafes no solamente revelan una reelaboración de la estrella cinematográfica sino que adelantan la estructura total de la obra.

Uno de esos reflejos más notorios es la "divergencia" entre título y contenido, escisión que aparece reelaborada metafóricamente de diversas maneras en la obra, como lo veremos en este artículo. De esta serie de reiteraciones encontramos dos grupos destacables, por un lado, encontramos la separación de "el nombre propio" y referente; y por otra, "el olvido del nombre".

Existen tres epígrafes que abordan el tema de "el olvido" -V, IX, XVI-, y dos que exponen la problemática del "nombre propio", IV, VIII. En relación con "el olvido", en el V, Jean 
Harlow dice haber olvidado las palabras de su esposo; en el IX, Susan Hayword toma alcohol para olvidar en dolor de haber perdido el único hombre que ama; en el XVI, Rita Hayworth finge no recordar el nombre de su amado. En el caso del "nombre propio", en el IV, Marlene Dietrich impresiona al Oficial Inglés al revelarle su identidad por medio del nombre exótico "Shangai Lilly"; en el VIII, Hedy Lamarr es comparada con París, "La Ciudad de las Luces".

\subsection{El olvido}

Puig reelabora los objetos de consumo masivo de la misma manera que Gladys realiza esculturas con desechos dejados por la marea. Esta amalgama incluye tanto las llamados productos de "alta cultura" como los de "baja". Dentro de esta mezcla encontramos el psicoanálisis, y, especialmente en The Buenos Aires Affair, el olvido (Freud 1980: 1-9). Este, -y su contraparte- el recuerdo son claves en la obra en estudio ya que "intencionalmente" se olvidan unos elementos pero se reiteran otros.

La novela cuenta la historia personal de Gladys Hebe Onofrio y de Leopoldo Druskovich; entonces, vamos a conocer detalles de sus vidas desde la infancia hasta el momento del falso asesinato. El texto muestra una necesidad de incluir detalles que explican principalmente las frustraciones sexuales de la pareja; finalmente, el relato nos deja entrever por qué el crítico de arte lleva a cabo su plan. La manera de contar estas biografías recuerda los casos reportados por el médico vienés a través de sus escritos. También, ello nos remite a la interpretación popular de este saber en las revistas de modas. Leemos en la novela:

\footnotetext{
Una mañana Gladys entró a la clase con la vista baja, Fanny le dio un codazo porque no lo había saludado y Gladys al decir "hola" mostró sus dientes delanteros tomados por un aparato de ortodoncia. Debía llevarlos cuatro años, hasta después del baile de quince; necesitaba desahogarse y con una lágrima en los ojos se aventuró a una confesión, le contó que cada día que pasaba se agravaba su angustia de existir. Fanny, como dijo que según el psicoanálisis la angustia no provenía de ser sino de no ser como pretendíamos (1993: 31).
}

Tanto en esta novela como en otras del escritor argentino, el psicoanálisis se hace presente y funciona para simplificar y explicar la realidad. Sin embargo, esta disciplina no llega al lector vía referencias académicas; más bien, pasa por medio de los medios de comunicación masiva y llega en una versión simplificada. Específicamente, en la novela, la conexión se establece con las revistas en la forma de "test" y como una simple lectura. En relación con la cita anterior, y a través de la novela en estudio, Gladys y otros personajes "reales" de la historia olvidan para evidenciar su frustración sexual. Entonces, para la Diva, el olvido es consciente y lleva un propósito que el lector puede determinar; por el contrario, para Gladys es un acto involuntario que refleja la tragedia advenediza de una escultura tuerta.

Para Gladys, como afirmamos anteriormente, el olvido es falso y es una estrategia para reaccionar contra figuras masculinas. Dicho de otra manera, la "Star" muestra un control absoluto de sus acciones contrario a la escultora tuerta, quien siempre es víctima de su destino. Entonces, podemos asegurar que el olvido expresa la natural escisión entre el mundo "real" y el mundo del celuloide; además, viene a explicar la razón por la cual Gladys se reinventa su vida a partir de las glamorosas estrellas. Todo ello sucede porque "la angustia no provenía de ser sino de no ser como pretendíamos" (1993: 31). Particularmente en esta novela, Gladys "olvida" al exponerse al acontecimiento vergonzoso de tener que declamar con su madre: 
Cuando se levantó el telón para dar comienzo a la segunda parte madre e hija se hallaban en el escenario, sentadas en sendas sillas, con un mantel en la mano haciendo de bandera. La niña comenzó el diálogo con voz estrangulada por el miedo, la madre contó con profesionalismo consumado. La niña continuó, alabando las puntadas que daba su madre en el paño patrio con manos habilísimas (...). De repente en la sala se produjo un silencio inusitado: Gladys había olvidado la letra (...). Caído el telón Gladys corrió a la letrina de los camarines y se encerró (1993: 29).

La situación que la joven está viviendo es producto de todos esos eventos repetidos y frustrantes que se fueron convirtiendo en olvido. No solo para ella sino también para Leo, los olvidos son significativos y ayudan a explicar la vida incompleta; en otras palabras, el texto propone que la explicación para la impotencia sexual de Leo, y para la vida frustrada de la escultora se encuentran en el pasado de la pareja.

Madre e hija establecen una relación difícil desde sus primeros años. En ambos casos, es decir, en el de la niña y en el de la estrella, el olvido se muestra como un mecanismo de defensa. La diferencia radica en que, a través de la novela, la estrella asume el olvido como un acto voluntario sobre el cual tiene control; por el contrario, en el caso de Gladys niña, y en el de la madre como declamadora, es una acción involuntaria. A la madre le sucede similar:

\footnotetext{
Arte plásticas, su hija era artista, como ella misma, ambas demasiado sensibles, concluyó Clara Evelia. “...de la casa en hombros/ lleváronla al templo/ y en una capilla/ dejaron el féretro (...)” ¿cómo continuaban esos versos? Sólo recordaba que eran palabras dolorosas las que seguían. Como de muy lejos le pareció escuchar una voz, ¿de dónde provenía? Apenas lograba traspasar el cristal de la ventana y la cortina de gasa. Clara permaneció quieta un momento, pero no oyó nada más. Tampoco logró recordar el resto del poema (1993: 11).
}

Por el contrario, Jean Harlow finge olvidar para enfatizar su odio, por eso le dice a su marido: "Ni siquiera recuerdo lo que me dijiste hace un minuto" (1993: 71); más exactamente, el mismo acto adquiere un sentido activo y retador. Gladys, por el contrario, lo usa para mostrar su descontento ante la obligación de la madre; y, Clara Evelia, para llenar el hueco que dejó la partida de su "pequeña". En relación con esta última, siempre un acto interrumpe el olvido del poema y corta la concentración. Cuando Clara Evelia emprende su labor de ama de casa, y cuando nace Gladys, ella abandona la declamación y la escritura. Ese acto se repite en la Escena 1, cuando la madre busca a la hija y trata de rememorar sus poemas. Gladys estaba planeando suicidarse y el narrador nos informa sobre los pensamientos de ella:

\footnotetext{
si bien, despedirse telefónicamente de su madre sería doloroso para aquella, no concebía solución mejor; aunque debiese esforzarse, a su madre era preciso hablarse con claridad y calma; si bien la despedida sería triste, su desaparición a fin de cuentas resultaría un alivio para quien podría así retomar libremente sus actividades de recitadora (1993: 214).
}

Otro aspecto importante del olvido consiste en la relación que se establece entre el asesinato y la búsqueda del culpable. Recordemos que desde el principio de la novela se sugiere la pérdida de "alguien". Luego, Leo comete el crimen del baldío y, a través de la historia, el crítico de arte supone que es perseguido por el asesinato que no sabemos si finalmente se consumó. El miedo paranoico de haber matado y violado a un hombre, $-\mathrm{y}$ a veces, en medio de sus delirios, a una mujer- lo lleva a raptar a Gladys -escena inicial- y, consecuentemente, a su autoaniquilación en un accidente. Es decir, existe, una especie de olvido también acá.

El olvido produce las relaciones que generan la trama del relato. Por causas azarosas, la madre no mira en sentido inverso cuando sospecha la desaparición de Gladys. Eso habría acabado la trama. El texto no aclara qué habría advertido si denota esa presencia extraña. No son ni Gladys, ni Leo: 
La madre se puso de pie, no miró hacia la derecha donde habría percibido una presencia inesperada y corrió a buscar en el baño el canasto donde Gladys siempre colocaba los desechos que recogía (...). Volvió a la sala repitiendo el mismo recorrido en sentido inverso, por causas fortuitas no miró esta vez a la izquierda (1993: 13).

El detonante de la historia parece ser el olvido de echar la llave, es decir, cerrar la puerta del dormitorio. Eso ayuda a crear la atmósfera de falso suspenso del falso relato policiaco que estamos tratando. El fragmento de arriba y el inmediato nos permiten esclarecer una de las pistas de TBAA, cuyo resultado es otra bifurcación de sentido. El relato policial supone la solución de un crimen y, en la novela en estudio, ese acontecimiento nunca sucede. Las claves para resolver el misterio se encuentran ciegas a la lectura y es precisamente con el contraste de estas dos partes que estas pistas saltan a la vista:

El olvido, el descuido de echar llave a la puerta de la calle tal vez haya sido intencional, pero nadie lo puede certificar porque los psicólogos no pueden leer la mente de los pacientes (...) él pone un dedo contra los labios y pide silencio, ahora está tan cerca que sus palabras no se oyen en el dormitorio contiguo, me está hablando al oído (1993: 54).

El fragmento anterior sucede en junio de 68 y la escena 1, el 21 de mayo de 1969; dicho de otro modo, Gladys, un año antes, estaba describiendo la escena 1 de la novela TBAA. El nivel caótico de sentido en la novela en cuestión se basa en esta complejidad narrativa esbozada por elementos tan imperceptibles como una fecha colocada como "exergo". Gladys se erige como un escritor virtual y no como un simple narrador testigo, ya que ella crea todo el texto como lo haría cualquier escritor. Si ella es una "escritora", la reacción ante la madre es de repulsión, acto semejante a la sensación de envidia de la madre hacia Alfonsina Storni y Juana de Ibarbourou. Entonces, la progenitora logra recordar los versos mientras supone que su hija ha regresado a casa:

\footnotetext{
Improvisadamente había llegado a la conclusión de que su hija estaría ya emprendiendo el regreso a casa, porque también a ella le aterraban las tormentas (...) "cuando las maderas/ crujir el viento/ y azota los vidrios/ el fuerte aguacero/ (...) / Del húmedo muro tendida en un.../ tendida en un ...”¿cómo seguía? (...) ¡qué no hubiese dado por saber donde estaba su hija en ese momento? (...)/Del húmedo muro/ tendida en un.. en un... ¡hueco! /acaso de frío/ se hielan los huesos " logró por fin recordar (1993: 17).
}

Después de esclarecer esa pista oculta en una fecha y en el "olvido de echar la llave", hallamos ese "no recordar" como un "simple accidente", tanto en la madre como en Gladys. Opuestamente sucede con la estrella porque ella se lo autoinduce. La mise en abyme ocurre porque acontece como metáfora en ambos niveles narrativos: en el de Susan Hayward y en el de la escultora. La estrella y Gladys tienen problemas, en esta escena en particular, una con pastillas y otra con alcohol, pero el resultado final es el olvido:

\footnotetext{
Susan Hayward: ¿Para que voy a tomar?

Enfermera: (con buena intención) Le hará dormir toda la

noche.

Susan Hayward: No me gusta el alcohol.

Enfermera: Es bueno, ayuda a olvidar.

Susan Hayward: ¿Olvidar? ¿qué es lo que debo olvidar?¡El

amor de David? ...no es posible que lo único bueno que me

pasó en la vida haya terminado para siempre, ... pero estiro la

mano para tocarlo y en la oscuridad no hay nada...no puedo

tocar nada, y esa nada no es él, esa nada soy yo...(la

enfermera acerca el vaso a los labios de la paciente...) (1993: 136).
} 
En el texto, el olvido involuntario se vuelve voluntario al ser narrado, entonces, Hayward finge no recordar. El asunto amoroso y, después, la pérdida de un cuerpo y un supuesto crimen nunca ocurrido dan forma a esa gran cantidad de detalles que suceden una y otra vez. Leamos:

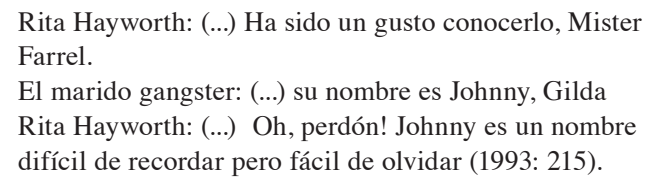

Las pistas en la obra no tienen fondo ni referencia. No remiten a un crimen si las leemos con cuidado y, por esta razón, la obra se plantea como novela policíaca pero en el hecho es una parodia. Todo es una invención poética materna y Gladys es producto de esa creación. Los olvidos de la madre y los silencios poéticos se refieren a la hija como una sustitución de esos silencios. Ese cuerpo olvidado es poesía cursi de la madre como lo es el nombre de la hija.

\subsection{El nombre propio}

En la novela en estudio, tanto símbolos-objeto como palabras se dirigen a resaltar una estética "popular" y exagerada. Así, el vestuario multicolor y platino de la diva y las poesías sentimentales y dramáticas de la madre cumplen el objetivo determinado de "pintarrajear" y "volver excepcional" a Gladys y a las "vamps". Esta decoración aparece en casi todos los epígrafes y se reelabora en el uso del nombre efectista en los paratextos IV, VIII, XV.

Sobre el nombre propio, la novela despliega una serie de relaciones complejas que van desde la "criptografía" del título hasta la sustitución del nombre del personaje por el de la estrella en los paratextos. Dicha forma nominal deja de ser la "etiqueta" particular de un sujeto u objeto para volverse simplemente un envoltorio decorado. Es una metáfora de la cultura cinematográfica y a su vez, dentro de la evolución de la novela, se vuelve una referencia al kitsch.

En los tres epígrafes, se remarca un sustantivo propio que automáticamente remite a una persona o nombre de importancia. Primero, en el IV, se produce el sobresalto ante el nombre "Shangai Lilly, la Flor Blanca de la China"; segundo, en el VIII, se pronuncia el nombre de la ciudad luz "París" y, de este modo, se evoca un espacio referente en la cultura universal y cinematográfica. Finalmente, sucede el olvido del nombre "Johnny", quien había sido el único hombre amado por Rita Hayworth -o Gilda en su personaje cinematográfico-. En los tres casos, el "sobresalto es positivo", contrario al rechazo por al nombre "Gladys".

LD: Ella va a terminar mal.

MEV:

LD: ¡Gladys!;Gladys!;Gladys! Es nombre ridículo.

MEV

LD: Yo sé que va a terminar mal, se va a matar. Y ojalá se matase ya" (1993: 147).

El nombre de Gladys es ridículo, por la misma razón que las actrices de los epígrafes cambiaron sus nombres reales a otros que eran "bellos" y tenían estilo, dentro del cine esos nombres "evocan" visualmente un ser especial; pero, en la ficción de la novela, el nombre Gladys remite el decorado cursi de las metáforas de la madre. Más precisamente, la joven es un ser "real" que no puede apropiarse de las fórmulas identificativas de esos seres llamados Divas. 
Como los epígrafes remiten al mundo de la fantasía fílmica para nosotros como lectores y también para los personajes de la novela, entonces la estrella es un ser doblemente especial porque es un ser "sagrado", tanto para los personajes de la novela como para nosotros los lectores. Ella tiene el derecho de jugar con la palabra y oscurecer significados, hecho que, en el caso de las mujeres de la novela, resulta motivo de sanción. Por ello Gilda puede olvidar:

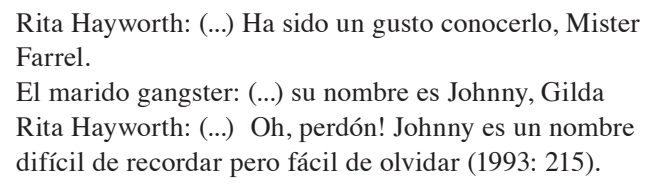

Como en todo texto poético, la palabra se conecta con el sujeto que pretende sustituir y su enunciación provoca asombro. Es decir, Margarita Cansino, Mary Leta Dorothy Slanton o Harlean Carpenter carecen de existencia para la cultura; pero si trasformamos esos nombres en Rita Hayworth, Dorothy Lamour o Jean Harlow, respectivamente, surge un referente particular que es el de la pantalla y el del "star system". En la siguiente cita, el no reconocer el nombre compromete al Oficial Inglés. Exactamente, en los epígrafes, el nombre del personaje ficticio es portador de sentido mientras que éste en el texto es ridículo y paródico:

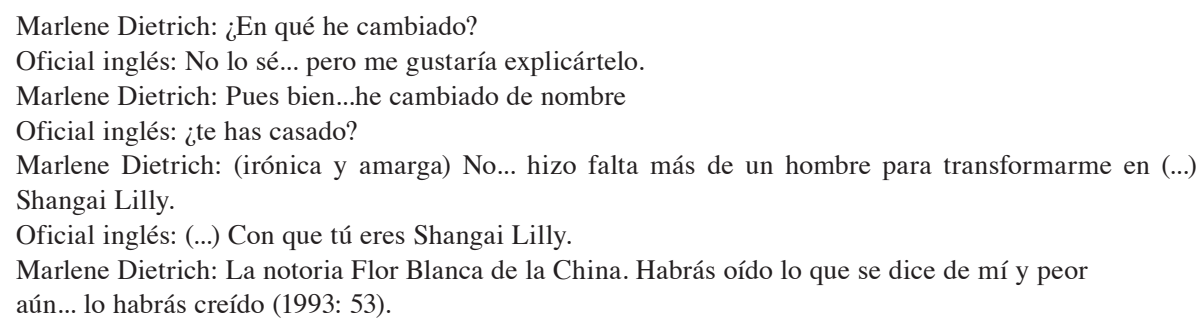

Otro aspecto destacable en torno al uso del nombre es la referencia a escritores, músicos e intelectuales; también, este rasgo implica la mención iconos de la cultura popular, del arte y del saber académico mezclados con actitudes y modos de consumo masivo. Para ejemplificar, Gladys lee Thomas Mann, Herman Hesse y a la vez elabora mentalmente el sueño de ser entrevistada por Harper's Bazar, especie de revista de modas.

El uso de nombres, como apelación a la autoridad, ocurre de tal manera que, al contrastarlos con otros elementos de "baja cultura", entran a formar parte de la forma caricaturesca de Gladys. Ella es un monigote no solo por su parche en el ojo, también lo es por su madre "Declamadora Cursi", por sus trabajos artísticos carentes de talento, por su ridícula vida social y por su vida sexual frustrada.

Para enfatizar ese contraste de la mezcla de "culto" y lo popular", el día en que Gladys fue engendrada, Clara Evelia y su esposo, Pedro Alejandro, venían de una representación de El Gran Dios Brown de O'Neill. El nombre de esta obra es importante dado que se habla del Arquitecto del Universo y, esa misma noche, Gladys es concebida. La madre "quería dar un beso lleno de gracia y exquisitez" (1993: 25) y el marido, simplemente "se despertó, y terminando el acto sexual le pidió a su esposa que le repitiera algo lindo de lo que había leído esa noche" (1993: 25). Finalmente, esa petición le molestó porque hubiera preferido que le pidiera algunas líneas de su autoría. Clara Evelia vive en función de modelos literarios que, a pesar de ser de gran calidad, se asocian popularmente con el sentimentalismo y la difusión masiva. Producto de esa mezcla, nace Gladys y ella queda marcada por esa combinación: 
De vuelta a casa Clara Evelia expresó su deseo de releer a sus maestros Nervo y Darío, su esposo habría preferido apagar la Luz en el mismo momento de acostarse(...) Se volvió a acostar y no pudo evitar la irrupción de dos nombres consagrados que la humillaban: Juana de Ibarbourou y Alfonsina Storni. Clara Evelia sentía la boca agria, se imaginó a sí misma verde y con ojeras negras, encarnación de la envidia (1993: 25).

El nombre evoca una autoridad, pero el problema no radica en las denominaciones empleadas para reconocer a los hombres, el problema se encuentra en la utilización de estos para identificar a las mujeres. La madre declamadora de poesía "cursi" escribe y declama para rememorar esos cuatro maestros de la literatura latinoamericana. El producto es "texto lugar común", que se extiende hasta la nombre de Gladys como producción significante. La reacción de rechazo que la madre siente hacia las escritoras es la misma que Gladys experimenta más tarde por su progenitora:

\begin{abstract}
A los cinco años fue enviada al Jardín de Infantes "Pulgarcito" de gestión privada. La maestra le enseñó una poesía y la niña la aprendió con mayor rapidez que sus compañeros. (...) Clara Evelia estaba sorprendida porque la niña siempre se había negado a aprender con ella aun la más corta de las poesías. Una vez llegadas a casa la madre le pidió a la niña que la recitara. Gladys se resistía (...) La niña recitó, Clara Evelia dijo que esa maestra era un "caballo" y que los alemanes que le habían enseñado eran de "caballo". La niña la miró desafiante y le dijo que la maestra recitaba mejor que Clara Evelia porque era más linda. Por primera vez se le ocurrió comparar las manos de la maestra, delgadas, color rosa pálido, de uñas pulidas pero cortas y sin esmalte, con las manos de su madre, de oscuros dedos mate manchados de tabaco y uñas largas arqueadas pintadas de rojo bermellón (1993: 27-28).
\end{abstract}

En los epígrafes, el nombre de la estrella se carga de un sentido positivo porque permite que el lector la identifique con el mercado cinematográfico, el cual previamente se ha encargado de erigirla como un ser bello y famoso. Por el contrario, en la fícción de TBAA, sucede una reacción negativa ante el nombre de la escultora; sumado a este rechazo, encontramos a "la madre" que siente envidia hacia las famosas escritoras suramericanas. En los paratextos, se llega incluso a metaforizar a la estrella como un espacio geográfico especial, "La Ciudad Luz" y eso significa una magnificación de ella:

\footnotetext{
El ladrón: (estrechándola en sus brazos)¡Eres hermosa!

Pero eso es tan fácil decirlo...Te lo habrán dicho hasta el cansancio. Lo que yo quiero expresarte es diferente. Para mí eres más que hermosa (...)¿Sabes lo que tú eres para mí?;París!...Eso eres tú ¡París entera!” (1993: 121).
}

El nombre de la Diva es importante, mientras que el de la escultora es una ridículo. En la siguiente cita, encontramos a Gladys mientras lee el pequeño anuncio de periódico en el cual se da a conocer que Leo finalmente eligió a María Ester y no se menciona su nombre. Ella no se inmuta ante la omisión y la presencia de la "otra". Ambos pierden el efecto que tienen los de los epígrafes:

\footnotetext{
En la sección segunda había un recuadro con el anuncio de la designación de María Esther Vila como representante argentina en la Bienal de San Pablo sin hacer alusión a la candidata previa. Gladys leyó en la columna vecina el programa semanal correspondiente a la temporada lírica del Teatro Colón (...). Sus razonamientos sucesivos, en términos resumidos fueron lo que siguen: a pesar de haberlo deseado mucho, nunca había visto la ópera Turandot de Puccini y por lo tanto era posible que no llegase a verla (1993: 209).
}

Los nombres de las mujeres en la historia no producen el mismo efecto de autoridad que los usados en epígrafes y distan mucho del efecto que generan los varones de la historia. El día que Gladys conoció a Leo ya había entablado amistad con unos muchachos de aspecto "hippie”, en Playa Blanca; cuando ellos vieron sus esculturas, sucedió lo siguiente: 
Decían que mis obras querrían ellos haberlas realizado y esa tarde fuimos todo juntos al mar. Leo Druskovitch, lo único que lamentaban era que con nosotros no estuviera Leo Druskovitch. Leo Druskovitch ¿quién es? Y todos soltaron la más bonachona de las carcajadas. "El Zar de la Crítica Plástica" (1993: 10).

El nombre de Druskovitch lleva un tono de autoridad, incluso semeja a esos hombres de preferidos de las fantasías de Gladys. Por el contrario, en los epígrafes, los varones son infantilizados, tienen algún modo dudoso de ganarse la vida o son amenazados. Adjuntamos a esta característica que, mientras en el paratexto se da a conocer el nombre de la estrella, el varón es conocido solo por su profesión.

A manera de conclusión, los epígrafes buscan el efecto de transportar al lector, mediante una ligadura compleja, al mundo del glamour del celuloide, esto abre un espacio donde las reglas son diferentes, si lo comparamos con el mundo de TBAA. El mismo objeto, en este caso, el nombre propio de la "actriz", consigue efectos diferentes en espacios diferentes. De hecho, quizá el rasgo más sobresaliente a simple vista consiste en que en los paratextos, el sustantivo propio en el filme referido se sustituye por el del actor. Este hecho expresa su importancia en ese lugar. "Gladys" produce risa o repulsión y la poesía es ridiculizada por las declamaciones de la madre. En el caso de los personajes masculinos, no sucede nada destacable, y con otras mujeres de la obra, acontece un desplazamiento de sentido que estudiaremos en el próximo apartado.

\section{Bibliografía}

Amícola, J. y G. Esperanza. 1998. Encuentro internacional Manuel Puig. Buenos Aires: Orbis Tertius. Facultad de Humanidades y Ciencias de la Educación de Mar del Plata.

Amícola, José (comp.). 1984. Homenaje a Manuel Puig. Serie: Estudios e Investigaciones. Buenos Aires: Universidad Nacional de la Plata. Facultad de Humanidades y Ciencias de la Educación.

Amícola, José. 1996. Materiales iniciales para La Traición de Rita Hayworth. Buenos Aires: Centro de Estudios de Teoría y Crítica Literaria.

Ancheschi et at. 1990. Las videoculturas de fin de siglo. Madrid: Ediciones Cátedra.

Bajtin, Mijail. 1998. Problemas de la poética de Dostoievsky. México: Fondo de Cultura Económica.

1986. Problemas Literarios y Estéticos. La Habana: Editorial Arte literaria.

Barthes, Roland. 1972. Critical Essays. Illinois Northwestern University Press.

1990. Fragmentos de un discurso amoroso. México: Siglo XXI.

1982. Lo obvio y lo obtuso, Barcelona: Editorial Paidos. 
1992a. La aventura semiológica. Barcelona: Ediciones Paidos.

1992b. El susurro del lenguaje. Más allá de la palabra y la escritura. Barcelona: Ediciones Paidos.

Baudrillard Jean.1976. La génesis ideológica de las necesidades. Barcelona: Editorial Anagrama. 1983. De la seducción. Madrid: Ediciones Cátedra.

Bell Metereau, Rebeca. 1993. Hollywood Androginy. New York: Columbia University Press. Bennington, Jeoffrey. 1994. Jacques Derrida. Madrid: Editorial Cátedra.

Bettelheim, Bruno. 1990. Psicoanálisis de los cuentos de hadas. Barcelona: Editorial Crítica. Butler, Judith. 2001. El género en disputa. México: Paidos.

Casetti, Francesco. 1994. Teorías del cine. Madrid: Ediciones Cátedra.

Cohn, Dorrit. 2003. "La mètalepse et la mise en abyme”. http://www.vox-poetica.org/t/ metalepse.htm. Consulta: 10 de marzo de 2007.

Cortés, Maria Lourdes. 1999. Amor y Traición. Cine y Literatura en América Latina.. San José: Editorial de la Universidad de Costa Rica.

Dällenbach, Lucien. 1991. El Relato Especular. Madrid: Visor.

Deleuze, Gilles. 1972. Repetición y diferencia. Barcelona: Editorial Anagrama. 1992. Differénce et répétition. París: Presses Universitaires de France.

De Peretti, Cristina. 1989. Derrida. Texto y deconstrucció. Barcelona: Editorial Anthropos.

Debord, Guy. 1992. La société du Spectacle. París: Editions Gallimard.

Derrida, Jacques. 1989. Márgenes de la filosofía. Madrid: Ediciones Cátedra.

Duran, Armando. 1973. Estructura y técnicas de la novela sentimental y caballeresca. Madrid: Editorial Gredos.

Eagleton, Terry 1976. Marxism and Literary Critisism. Los Angeles: University of California Press. 
1983. Literary Theory An Introduction. Minesota: University of Minessota. Press.

Eco, Umberto. 1977. Apocalípticos e integrados. Barcelona: Lumen.

Edgerton Gary et al. 1988. Film and the arts in symbiosis. New York: Greenwood Press.

Einsentein, Sergei. 1990. Reflexiones de un Cineasta. Barcelona: Editorial Lumen.

Ellison, David R. 1993. Of Words \& the World: Referential Anxiety in Contemporary French Fiction. New Jersey: Princeton University Press.

Escohotado, Antonio. 2000. Caos y Orden. Madrid: Espasa.

Fernández Moreno, César. 1977. América Latina en su Literatura. México: Siglo XXI.

Fokkema, D y I. Elrud. 1981. Teorías de la literatura del siglo XX. Madrid: Ediciones Cátedra.

Freud, Sigmund. 1965. The interpretation of dreams. New York, A Books.

1980. Psicopatología de la vida cotidiana. Madrid: Biblioteca Nueva.

1985.Obras completas 3. Madrid: Editorial Biblioteca Nueva.

Gabrielle, John. 2005. "Narrative Prisms and Prisons. Mirror effects and mise en abyme in Don Quijote”. Symposium. 1 (59): 31- 43. Recuperado 15 de febrero 2007 de la base de datos Elibro.

García Canclini, Néstor. 1995. Consumidores y ciudadanos. Conflictos multiculturales de la Globalización. México: Editorial Grijalbo.

García Ramos, José Manuel. 1991. La Semana de Autor sobre Manuel Puig. Madrid: Ediciones de Cultura Hispánica.

Genette, Gerard. 1987. Seuils. París: Edition de Seuils.

Goldschluk, Graciela. 2004. "Puig, escritor de cámara”. http://www.clarin.com/suplementos/ cultura/2004/07/24/u-800076.htm. Consulta: 22 de julio 2007.

Gubern, Román. 1977. Comunicación y Cultura de Masas. Barcelona: Ediciones Península. 1989. Historia del Cine. Madrid: Editorial Fondo de Cultura Económica. 
Hauser, Arnold. 1968. Historia social de la literatura y el arte. Madrid: Ediciones Guadarrama.

Henry, Karen. 2000. “Mise en Abyme”. Afterimage. 1 (28) 13. Recuperado 15 de febrero 2007 de la base de datos en Elibro.

Horkenheimer, M. y T. 1971. Adorno Dialéctica del iluminismo. Buenos Aires: Sur.

Hutcheon, Linda. 1988. History. Theory. Fiction. London: Cambridge University Press.

Jiménez Castro, Marjorie. 1993. La problemática del género en el texto. Boquitas Pintadas de Manuel Puig. Tesis de Licenciatura. Universidad de Costa Rica.

Kellner, Douglas. 1995. Media Culture. Cultural studies, identity and politics between the modern and the posmodern. London and New York: Rutledge.

Kerr, Lucille. 1987. Suspended Fiction, Reading novels by Manuel Puig. Urbana and Chicago: University of Illinois Press.

Krauskin, Margarita. 1996. La novelística de Alfredo Bryce Echenique y la narrativa Sentimental. Madrid: Editorial Pliegos.

Kristeva, Julia. 1988. Historias de Amor. Buenos Aires: Editorial Siglo Veintiuno.

Kuhn, Anette. 1991. Cine de Mujeres, Madrid: Ediciones Cátedra.

Landry, Chris. 2005. "Camp is a woman walking around in dress made of three million feathers: notes on: "Notes on camp". www.angelfire.com/ca/disgrutled/sontag/html. Consulta: 10 de marzo 2007.

Levine, Susanne Jill. 2002. Manuel Puig y la Mujer Araña. Barcelona: Editorial Seix Barral.

Lewin, Roger.1995. Complejidad. El caos como generador de orden. Barcelona: Tusquets.

Luhman, Niklas. 1990. Sociedad y sistema. La ambición de la teoría. Barcelona: Ediciones Paidos, Universidad Autónoma de Barcelona.

1998. Complejidad y Modernidad: de la unidad a la diferencia. Madrid: Editorial Trotta.

Mast, Gerald et al. 1992. Film theory and criticism. New York: Oxford University Press.

Mayersberg, Paul. 1971. La Casa encantada. Barcelona: Editorial Anagrama. 
Metz, Christian. 1972. Ensayos sobre la significación en el cine. Buenos Aires: Editorial Tiempo Contemporáneo.

1979. El significante Imaginario. Barcelona: Editorial Gustavo Gili.

Meyer-Minnerman, Klauss y Sabine Schlickers. 2004. "La mise en abyme en narratologie". www.vox-poetica.org/t/menabyme.html. Consulta: 10 de marzo 2007.

Moi, Toril. 1995. Teoría literaria feminista. Madrid: Ediciones Cátedra.

Morin, Edgard. 1972. Les Stars. París: Edition de Seuil.

Peña-Ardid, Carmen. 1996. Literatura y cine. Una aproximación comparativa. Madrid: Ediciones Cátedra.

Prado, Maritza. 2004. Voces y fuerzas centrífugas en la novela Desconciertos de un Jardín Tropical de Magda Zavala. Tesis de Licenciatura. Universidad de Costa Rica.

Puig, Manuel. 1993. The Buenos Aires Affair. Barcelona: Biblioteca de Bolsillo.

Ramírez Hernández, Rebeca. 2003. La eterna impaciencia por alcanzar la completud. El realismo del proceso de formación sentimental en Los Impacientes de Gonzalo Garcés. Universidad de Costa Rica.

Sharret, Christofer et at. 1993. Crisis Cinema. The apocalyptic Idea in the posmodern film Narrative. Washington: Maisoneuve Press.

Sadoul, Georges. 1984. .Historia del cine mundial - desde los orígenes hasta nuestros días. México: Editorial Siglo Veintiuno.

Sontag, Susan. (s.f.). "Notes on Camp". http://pages.zoom.co.uk/leverigdge/sontag.html. Consulta: 10 de marzo 2007.

Stemberg de Kaplan, Olga. 1989. Manuel Puig. Un renovador de la novela. Argentina: Universidad Nacional de Tucumán.

Thompson, Kristin y David Bordwell.1994. Film History. An introduction. US: Mc Graw- Hill. 2001. Film Art. An introduction. US: Mc Graw-Hill.

Vattimo, Gianni et at. 1994. En torno a la posmodernidad, Colombia: Editorial Anthropos. 
Walker, Alexander. 1969. Sex in the movies. London: Penguin Books.

1970. El estrellato. El fenómeno Hollywood. Barcelona: Editorial Anagrama.

Woolf, Sergio. 2001. Cine/ Literatura. Ritos de Pasaje. Barcelona: Paidos.

Yarza, Alberto. 1999. Un caníbal en Madrid. La sensibilidad camp y el reciclaje de la historia del cine de Pedro Almodóvar. Madrid: Ediciones Libertarias. 
